\author{
Ana F. DUARTE ${ }^{1,2}$ \\ Bernardo SOUSA-PINTO ${ }^{2,3,4}$ \\ Luís F. AZEVEDO ${ }^{2,3}$ \\ Ana M. BARROS \\ Susana PUIG ${ }^{5}$ \\ Josep MALVEHY ${ }^{5}$ \\ Eckart HANEKE ${ }^{1,6,7,8}$ \\ Osvaldo CORREIA ${ }^{1,2,4}$ \\ ${ }^{1}$ Centro de Dermatologia Epidermis, \\ Instituto CUF, Porto, Portugal \\ ${ }^{2}$ CINTESIS - Centre for Health Technology \\ and Services Research, University of Porto, \\ Portugal \\ ${ }^{3}$ MEDCIDS - Department of Community \\ Medicine, Information and Health Decision \\ Sciences, Faculty of Medicine, University of \\ Porto, Portugal \\ ${ }^{4}$ Basic and Clinical Immunology Unit, \\ Department of Pathology, Faculty of \\ Medicine, University of Porto, Portugal \\ ${ }^{5}$ Dermatology Department, Hospital Clinic \\ de Barcelona, Universitat de Barcelona, \\ IDIBAPS, Barcelona, Spain \& Centro de \\ Investigación Biomédica en Red de \\ Enfermedades Raras (CIBERER), Instituto \\ de Salud Carlos III, Barcelona, Spain \\ ${ }^{6}$ Department of Dermatology, Inselspital, \\ University of Bern, Bern, Switzerland \\ ${ }^{7}$ Dermatology Clinic Dermaticum, \\ Freiburg, Germany \\ ${ }^{8}$ Department of Dermatology, University of \\ Ghent, Ghent, Belgium
}

Reprints: Ana F. Duarte

$<$ duarte.af.t30@gmail.com>

Article accepted on 19/02/2021

\section{Clinical ABCDE rule for early melanoma detection}

\begin{abstract}
Background: The ABCDE rule systematizes warning signs for malignant melanoma (MM). Objectives: To evaluate whether the ABCDE signs are associated with early detection of MM. Materials \& Methods: Based on a retrospective study over 11.5 years, we assessed whether ABCDE signs are associated with early diagnosis of MM. Results: In total, $144 \mathrm{MM}$ were included; $52(36.1 \%)$ in situ and 92 (63.9\%) invasive lesions. For $23.6 \%$, the MM were first suspected by an individual other than a dermatologist. The "E sign" was significantly less frequent among in situ lesions ( $32.7 \%$ versus $50.0 \%$; $p=0.044)$. Based on adjusted analyses, the probability of MM being first suspected by a non-dermatologist consistently increased with the number of $\mathrm{ABCDE}$ signs of the lesion, ranging from $8 \%$ for a neoplasm with no ABCDE signs to $32 \%$ for a lesion with five signs $(\mathrm{OR}=1.6 ; 95 \% \mathrm{CI}: 1.2-2.2 ; p=0.004)$. Conclusion: A higher number of ABCDE signs were associated with a greater chance of MM being first suspected by a non-dermatologist, but not in situ MM diagnosis. Relying on the ABCDE rule alone might result in missing early MM lesions.
\end{abstract}

Key words: malignant melanoma $(\mathrm{MM}), \mathrm{ABCDE}$ rule, early detection, non-dermatologist
$\mathrm{M}$ alignant melanoma $(\mathrm{MM})$ is responsible for more than $80 \%$ of skin cancer mortality in Europe [1-4], accounting for 1-2\% of all cancer deaths $[5,6]$. In situ MM has an excellent prognosis, and its incidence is increasing at a higher rate than that of invasive melanoma, probably due to earlier detection [7-11].

Currently, strategies for early MM detection include full skin examination by the dermatologist and approaches to educate patients. The latter include teaching patients on how to identify suspicious lesions. The ABCDE rule and the "ugly duckling sign" (pigmented lesions that are clearly different from others in a given individual and, as such, should be the most suspicious) [12] are frequently recommended, as they are easy to learn and apply [8, 13-15].The ABCD rule, described by Robert Friedman in 1985, states that asymmetry (A), border irregularity (B), colour variegation $(C)$ and diameter generally greater than $6 \mathrm{~mm}(\mathrm{D})$ are features that would help early MM diagnosis [16]. In 2004, the "evolution" feature (E) - with respect to the size, shape, shade of colour, surface features or symptoms - was added to the rule, which recognizes the dynamic nature of $\mathrm{MM}$ malignancy [17]. Nevertheless, the ABCDE features might be present in benign lesions (such as solar lentigo or seborrheic keratosis) and are often absent (with exception of the "E" feature) in early melanoma and nodular melanoma [18-21].
Therefore, this study aimed to assess the usefulness of the ABCDE rule in the early detection of MM, namely by investigating whether $\mathrm{ABCDE}$ characteristics in patients with MM are more often present in in situ vs invasive MM and in melanomas first suspected by individuals other than dermatologists.

\section{Methods}

In this retrospective study, we assessed all patients diagnosed with MM between July 2007 and December 2018 in a private dermatology clinic in the North of Portugal. In all patients, the diagnosis of MM was clinically made by a senior dermatologist assisted by dermoscopy and confirmed by histopathological analysis. We excluded MM with Breslow depth $>2 \mathrm{~mm}$, nail melanoma and melanocytic tumours of uncertain malignancy, as well as neoplasms diagnosed in patients with genetic syndromes associated with multiple skin cancers and under immunosuppression for organ transplantation.

We recorded the morphological characteristics of each assessed MM, including those integrating the ABCDE rule. Lesion evolution (E) was assessed by patient questioning; absence or lack of knowledge on the occurrence of lesion 
evolution were assessed as corresponding to the same category. We also collected clinical information on the existence of the "ugly duckling sign", pigmentation pattern, anatomical location, and whether the lesion was palpable, as well as histological information about MM type, Clark level, Breslow depth, or associated nevi. Further retrieved patient information included gender, age at diagnosis, phototype, and past history of premalignant and malignant skin neoplasms.

Our outcome variables consisted of the stage at which the MM was diagnosed (in situ versus not in situ) and whether the MM had been first suspected by a dermatologist or by another individual (including the patient him/herself, a family member/friend or primary care provider).

\section{Statistical analysis}

Categorical variables were described using absolute and relative frequencies, while continuous variables were described using means and standard-deviations (SD) or medians and interquartile ranges (IQR). We applied classic inferential tests to assess the unadjusted associations between each recorded independent variable and each outcome variable-the chi-square test and Fisher's exact test were used to compare categorical variables, whereas the two-independent sample t-test and Mann-Whitney U test were used with continuous variables. Continuous variables were assessed on whether they followed a normal or non-normal distribution (by histogram assessment and Kolmogorov-Smirnov test) before application of descriptive or inferential statistics.

In addition, we performed binomial logistic regressions to test the associations between the number of ABCDE signs and each of the outcome variables-univariable logistic regressions were first performed, followed by multivariable regressions in which the number of signs was adjusted for a Generalized Propensity Score estimated through application of the Generalized Linear Models estimator. We calculated a Generalized Propensity Score (corresponding to the extension of propensity score methods to non-dichotomous exposures) rather than a "classic" propensity score, as the exposure variable (i.e., number of ABCDE signs) is not of the binary type. In fact, as the number of ABCDE signs is a count, we adapted the ordinary least square regression-based methods presented by Austin (which were described for continuous exposures with normal distribution) [22], computing the Generalized Propensity Score through application of the Generalized Linear Models estimator [23], assuming a Poisson distribution for the exposure variable. To calculate the Generalized Propensity Score, we regressed the number of ABCDE signs for patients' age, gender, phototype, past history of malignant or premalignant lesions, as well as anatomical location of the neoplasm, occurrence in photo-exposed areas, palpability, existence of associated nevus, and existence of the ugly duckling sign. We also used the computed Generalized Propensity score to estimate the dose-response functions for the six possible values of the number of ABCDE signs, adapting the methods described by Austin [22].

For baseline variables with missing data not surpassing 5\% of all cases (i.e., patients' phototype, existence of associated nevus, and past history of lentigo), missing data were replaced by values determined by Multivariate Imputation using the Chained Equations methods [24]. For those variables with more than $5 \%$ of missing data (i.e., diameter [mm] of the lesion, Breslow depth, and number of nevi), no data imputation was performed.

$P$ values lower than 0.05 were considered to be statistically significant. All statistical analyses were performed using software R (version 3.4.3), with use of the packages 'rms', 'mice' and 'ggplot2'.

\section{Results}

Between July 2007 and December 2018, we diagnosed a total of $165 \mathrm{MM}$, of which 21 were excluded based on the presence of nail melanoma $(n=9)$, melanocytic tumours of uncertain malignancy $(n=7)$, or MM with Breslow depth $>2 \mathrm{~mm}(n=5)$. Therefore, we assessed a total of $144 \mathrm{MM}$ from 138 different patients. Most MM were diagnosed in females $(n=87 ; 60.4 \%)$. The patients' mean age was 50.8 years (table 1). Fifty-two neoplasms (36.1\%) were identified as in situ. Thirty-nine MM (23.6\%) had been first suspected by an individual other than a dermatologist. Table 1 describes the morphological characteristics of the assessed MM as well as patients' demographic and clinical characteristics; overall values and results by stage at diagnosis and individual who first suspected the MM (dermatologist $v s$ other individual) are also presented in table 1 .

The indication of lesion evolution ("E" sign of the ABCDE rule) was significantly less frequent among MM diagnosed in situ $(32.7 \%$ versus $50.0 \%$ among the remaining cases; $p=0.044)$ and MM diagnosed by a dermatologist $(37.3 \%$ versus $64.7 \% ; p=0.005)$. The frequencies of the remaining ABCDE signs were not significantly different according to the stage at diagnosis or to the individual who had first suspected the MM (table 2, figure 1). In fact, the frequency of each sign was relatively low, ranging from $32.7 \%$ to $53.8 \%$ for in situ MM, and from $39.1 \%$ to $56.5 \%$ for non in situ MM. On average, the assessed MM had 2.4 ABCDE signs-similar average values were obtained for MM diagnosed in situ versus invasive (2.3 versus 2.4 , respectively; $p=0.668)$, and MM diagnosed by a dermatologist versus by other individuals ( 2.2 versus 2.8 , respectively; $p=0.150$ ) (table 2, figure 1).

Only $2.9 \%$ of MM suspected by individuals other than a dermatologist had a personal past history of skin cancer versus $24.5 \%$ of those diagnosed by a dermatologist ( $p=$ $0.005)$.

Based on unadjusted logistic regression analyses, the number of ABCDE signs were not associated with a significant change in the odds of melanoma being diagnosed in situ (odds ratio $[\mathrm{OR}]=0.9 ; 95 \%$ confidence interval $[\mathrm{CI}]=0.8$ $1.1 ; p=0.534)$ or of being first suspected by an individual other than a dermatologist $(\mathrm{OR}=1.2 ; 95 \% \mathrm{CI}=1.0-1.5$; $p=0.056$ ).

After adjusting for the computed Generalized Propensity Score (calculated based on clinical and demographic data), an increased number of ABCDE signs was associated with a non-significant decrease in the chance of a $\mathrm{MM}$ being diagnosed situ $(\mathrm{OR}=0.9 ; 95 \% \mathrm{CI}=0.7-1.1 ; p=0.377)($ figure 2$)$. By contrast, the probability of a melanoma being first suspected by an individual other than a dermatologist con- 


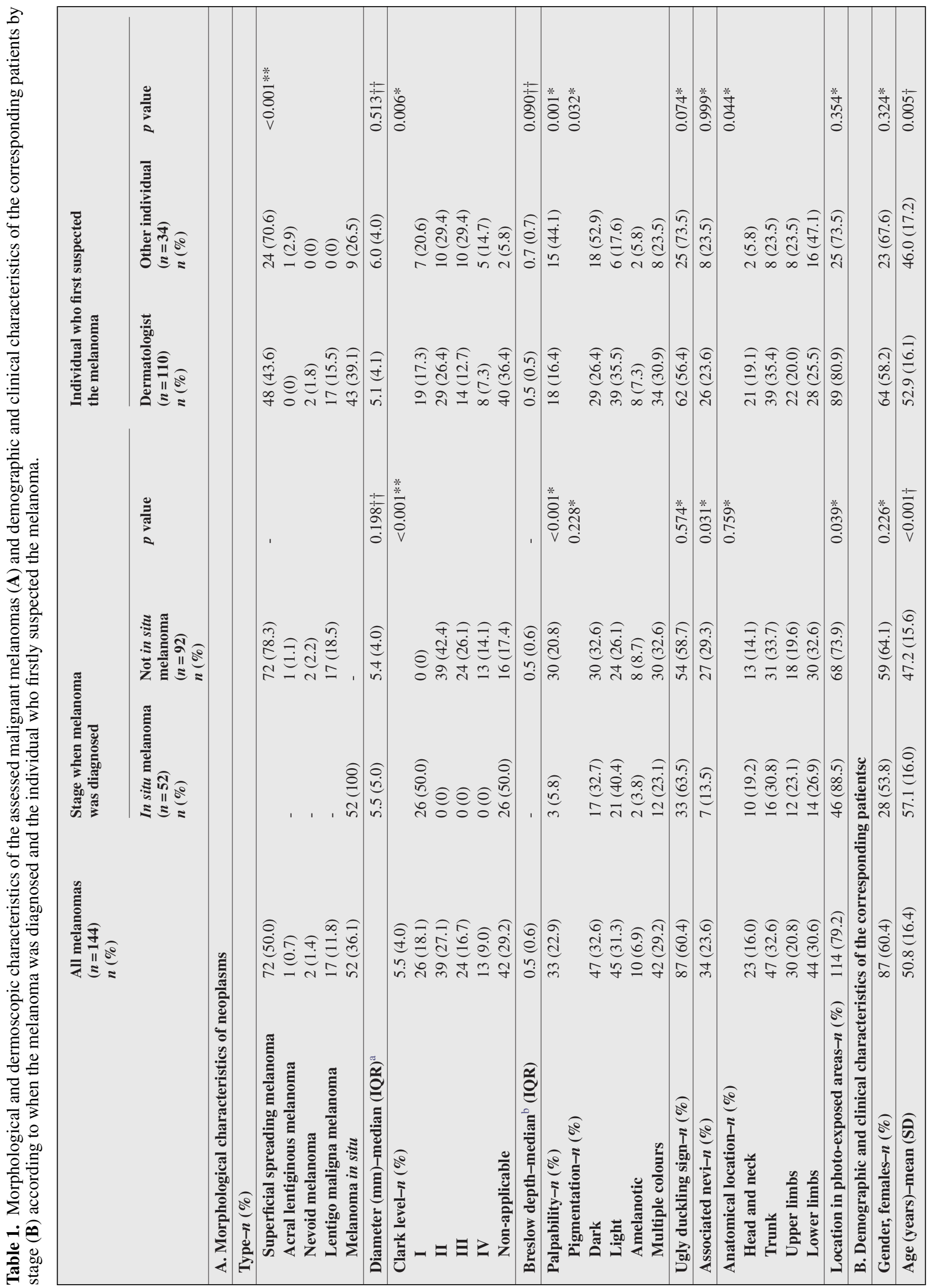




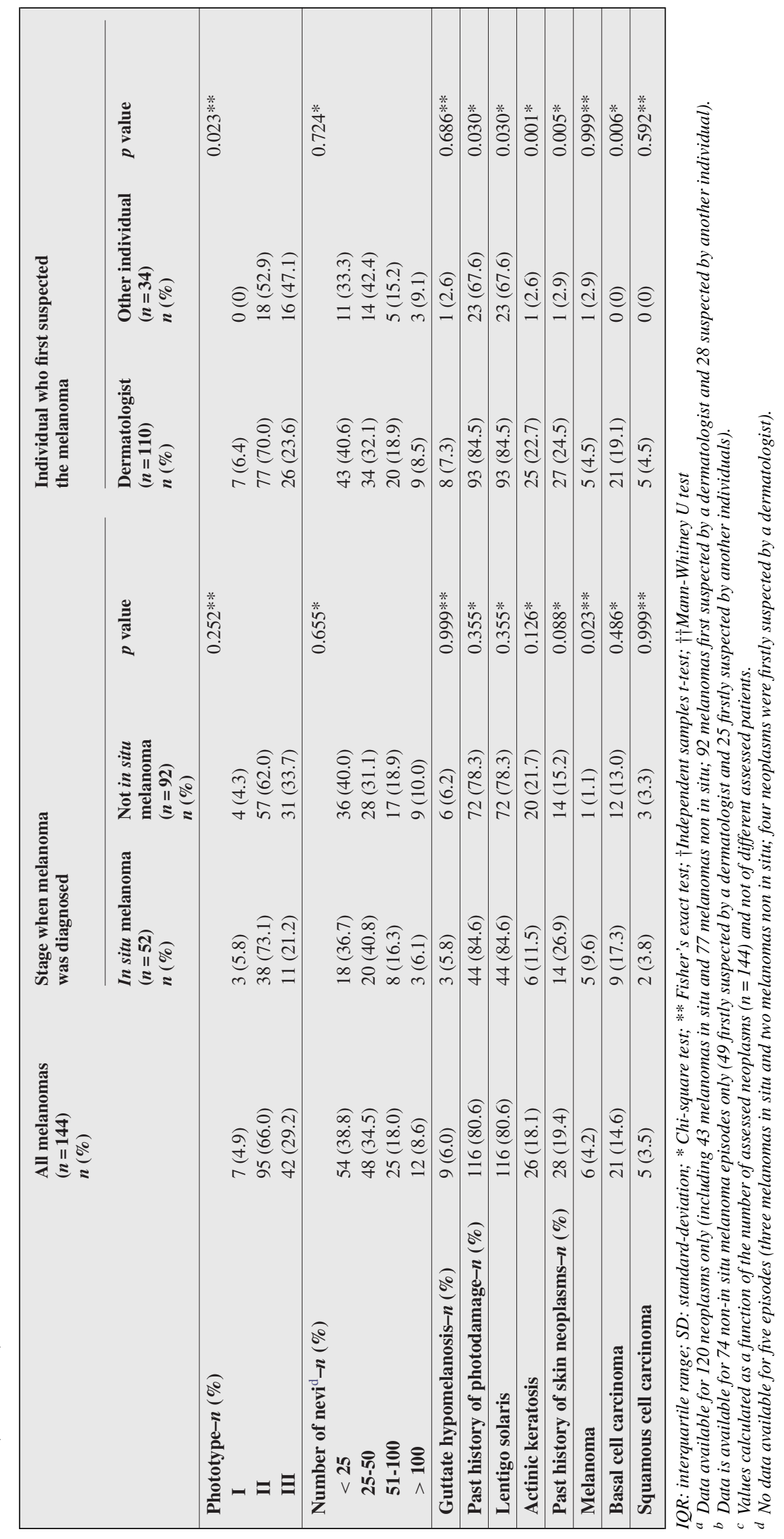


Table 2. Average number of observed ABCDE signs and frequency of each sign and of each sign count by stage according to when the melanoma was diagnosed and the individual who first suspected the melanoma.

\begin{tabular}{|c|c|c|c|c|c|c|c|}
\hline & \multirow{2}{*}{$\begin{array}{l}\text { All } \\
\text { melanomas } \\
(n=144) \\
n(\%)\end{array}$} & \multicolumn{3}{|c|}{$\begin{array}{l}\text { Stage when the melanoma was } \\
\text { diagnosed }\end{array}$} & \multicolumn{3}{|c|}{$\begin{array}{l}\text { Individual who firstly suspected } \\
\text { the melanoma }\end{array}$} \\
\hline & & $\begin{array}{l}\text { In situ } \\
\text { melanoma } \\
(n=52) \\
n(\%)\end{array}$ & $\begin{array}{l}\text { Not in situ } \\
\text { melanoma } \\
(n=92) \\
n(\%)\end{array}$ & $p$ value & $\begin{array}{l}\text { Dermatologist } \\
(n=110) \\
n(\%)\end{array}$ & $\begin{array}{l}\begin{array}{l}\text { Other } \\
\text { individual } \\
(n=34) \\
n(\%)\end{array} \\
\text { (\%) }\end{array}$ & $p$ value \\
\hline $\begin{array}{l}\text { No. of ABCDE signs-mean } \\
\text { (SD) }\end{array}$ & $2.4(1.7)$ & $2.3(1.9)$ & $2.4(1.7)$ & $0.668 \dagger$ & $2.2(1.7)$ & $2.8(2.0)$ & $0.150 \dagger$ \\
\hline 0 signs- $n(\%)$ & $33(22.9)$ & $18(34.6)$ & $15(16.3)$ & $0.012 *$ & $25(22.7)$ & $8(23.5)$ & $0.924 *$ \\
\hline 1 sign-n $(\%)$ & $19(13.2)$ & $3(5.8)$ & $16(17.4)$ & $0.048 *$ & $17(15.5)$ & $2(5.9)$ & $0.245 * *$ \\
\hline 2 signs $-n(\%)$ & $20(13.9)$ & $2(3.8)$ & $18(19.6)$ & $0.009^{*}$ & $15(13.6)$ & $5(14.7)$ & $0.999 * *$ \\
\hline 3 signs $-n(\%)$ & $21(14.6)$ & $8(15.4)$ & $13(14.1)$ & $0.838^{*}$ & $18(16.4)$ & $3(8.8)$ & $0.406^{* *}$ \\
\hline 4 signs $-n(\%)$ & $35(24.3)$ & $17(32.7)$ & $18(19.6)$ & $0.078^{*}$ & $29(26.4)$ & $6(17.6)$ & $0.300 *$ \\
\hline 5 signs $-n(\%)$ & $16(11.1)$ & $4(7.7)$ & $12(13.0)$ & $0.326^{*}$ & $6(5.5)$ & $10(29.4)$ & $<0.001 * *$ \\
\hline \multicolumn{8}{|l|}{ Frequency of each sign $-n(\%)$} \\
\hline Asymmetry (“A sign”) & $59(41.0)$ & $21(40.4)$ & $38(41.3)$ & $0.913^{*}$ & $43(39.1)$ & $16(47.1)$ & $0.409^{*}$ \\
\hline Irregular border ("B sign") & $79(54.9)$ & $28(53.8)$ & $51(55.4)$ & $0.854 *$ & $59(53.6)$ & $20(58.8)$ & $0.595^{*}$ \\
\hline Varied colour (“C sign”) & $60(41.7)$ & $24(46.2)$ & $36(39.1)$ & $0.412 *$ & $45(40.9)$ & $15(44.1)$ & $0.740 *$ \\
\hline Diameter $>6 \mathrm{~mm}$ ("D sign") & $81(56.3)$ & $29(55.8)$ & $52(56.5)$ & $0.929 *$ & $59(53.6)$ & $22(64.7)$ & $0.255^{*}$ \\
\hline Lesion evolution ("E sign”) & $63(43.8)$ & $17(32.7)$ & $46(50.0)$ & $0.044 *$ & $41(37.3)$ & $22(64.7)$ & $0.005^{*}$ \\
\hline
\end{tabular}

SD: standard-deviation; *Chi-square test; **Fisher's exact test; $\dagger$ Independent samples t-test.

sistently increased with the number of ABCDE signs of the lesion (ranging from $8 \%$ for a neoplasm with no ABCDE signs to $32 \%$ for a lesion with five signs) (figure 2), with this adjusted association being statistically significant $(\mathrm{OR}=1.6 ; 95 \% \mathrm{CI}=1.2-2.2 ; p=0.004)$.

\section{Discussion}

In this study, we assessed 144 cases of MM, of which more than a third had been diagnosed in situ. Most invasive cases were thin with a median Breslow thickness of $0.5 \mathrm{~mm}$. Only one quarter had been first suspected by an individual other than a dermatologist. We observed that the frequency of most $\mathrm{ABCDE}$ signs did not differ between "earlier" and later detected/suspected lesions. In addition, an increased number of ABCDE signs was not associated with a greater chance of MM being diagnosed earlier (i.e. in situ), despite being associated with a higher level of suspicion by an individual other than the dermatologist. This is not contradictory, as in more advanced neoplasms, the lesion changes are probably easier to detect by untrained eyes. That is, the probability of a lesion being suspected by an individual other than a dermatologist increased with the number of ABCDE signs.

Although the ABCDE rule has been described with good semiological value in the differential diagnosis of pigmented melanocytic lesions [25], in this study, only the "E" feature was negatively associated with detection of in situ lesions and lesions suspected by an individual other than a dermatologist. The ugly duckling sign was not associated with statistically significant differences either. These features might be of particular interest to alert patients who do not have easy access to dermatology specialists.
This study has some limitations, particularly regarding its retrospective design. It was based on data from a single private healthcare institution, with most lesions diagnosed at early stages. It is possible that the included patients were more strictly followed and had more frequent contact with a dermatologist (with routine full-body examination and regular photographic documentation with dermoscopy) than patients from other settings. This potential selection bias could partially explain the high frequency of neoplasms detected as in situ and may have resulted in an underestimation of the use of $\mathrm{ABCDE}$ for the detection of early MM. While the demographic characteristics of the patients assessed are mostly consistent with those of other series described in the literature [26-28], the low Breslow values found suggest that less advanced cases of MM may have been over-represented in our sample. Another important limitation concerns the fact that absence and lack of knowledge of the evolution of skin neoplasms ("E" sign) were assessed together as a single category. We opted for this joint assessment as both situations imply that evolution of the neoplasm was not detected by the patient (or those contacting him/her), as the $\mathrm{ABCDE}$ rule is used by patients themselves.

This study also has some important strong points. In particular, we assessed early detection of MM by taking into account both the stage of the lesion and the individual who had first suspected it. In addition, we used propensity scores to control for potential confounding variables when assessing the associations between the number of $\mathrm{ABCDE}$ signs and early detection of MM. Of note, as far as we know, this is the first study applying propensity scores to an exposure variable consisting of a count. There was limited information regarding the use of the ABCDE rule by non-dermatologists for in situ and invasive melanoma, which would add important information in this field. 

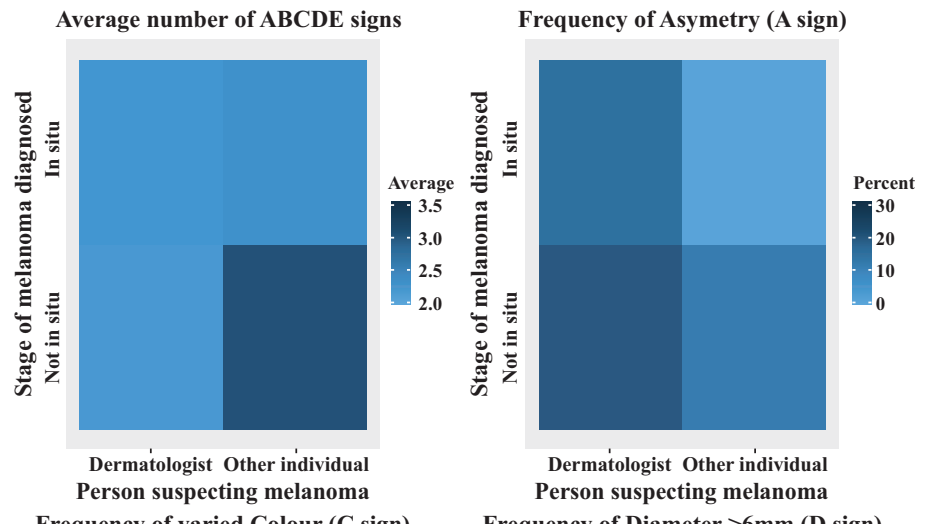

Frequency of irregular Border (B sign)

Frequency of varied Colour (C sign)

Frequency of Diameter $>6 \mathrm{~mm}$ (D sign)
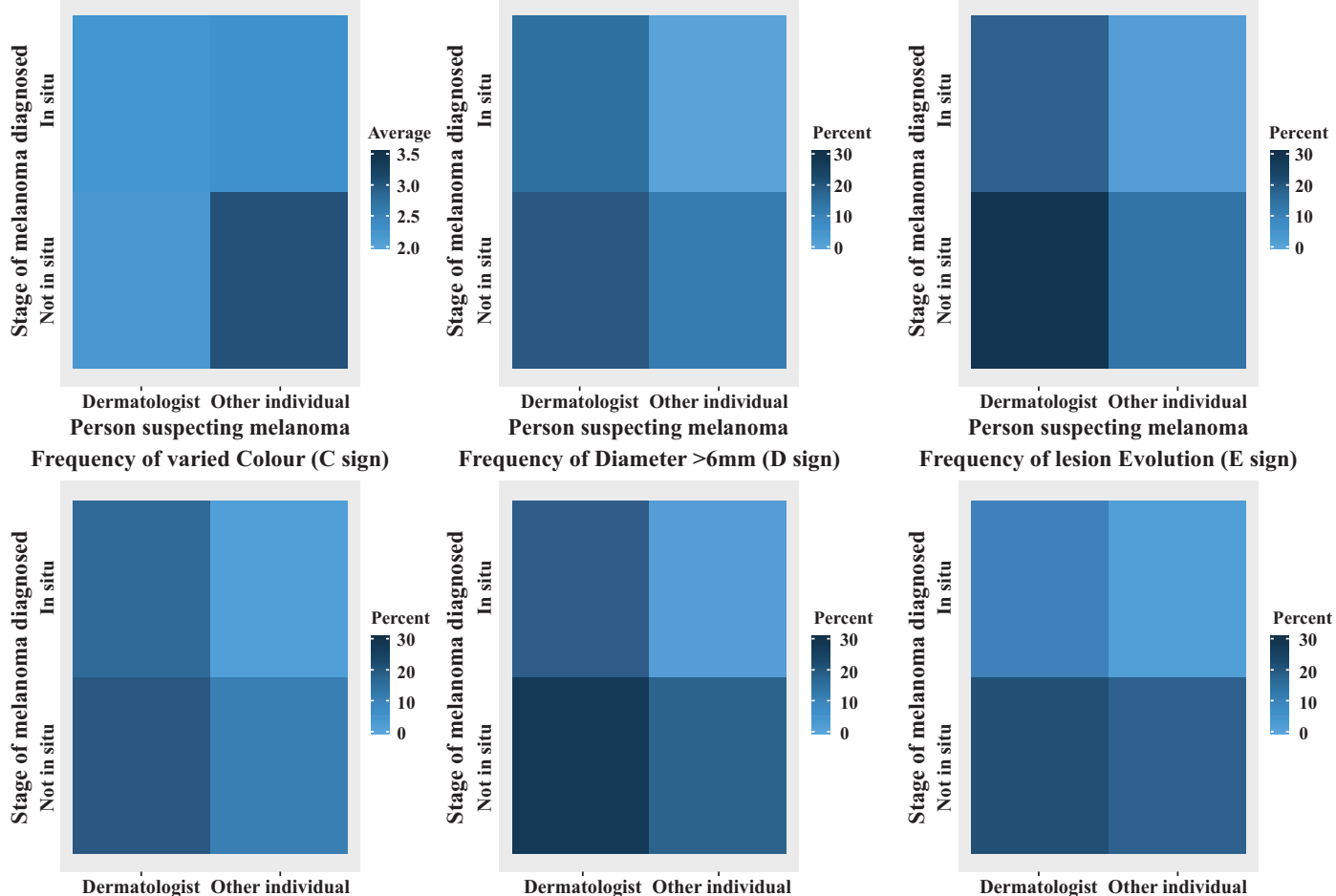

Person suspecting melanoma

Dermatologist Other individual Person suspecting melanoma

Frequency of 1 ABCDE signs

Frequency of lesion Evolution (E sign)

Frequency of $0 \mathrm{ABCDE}$ signs
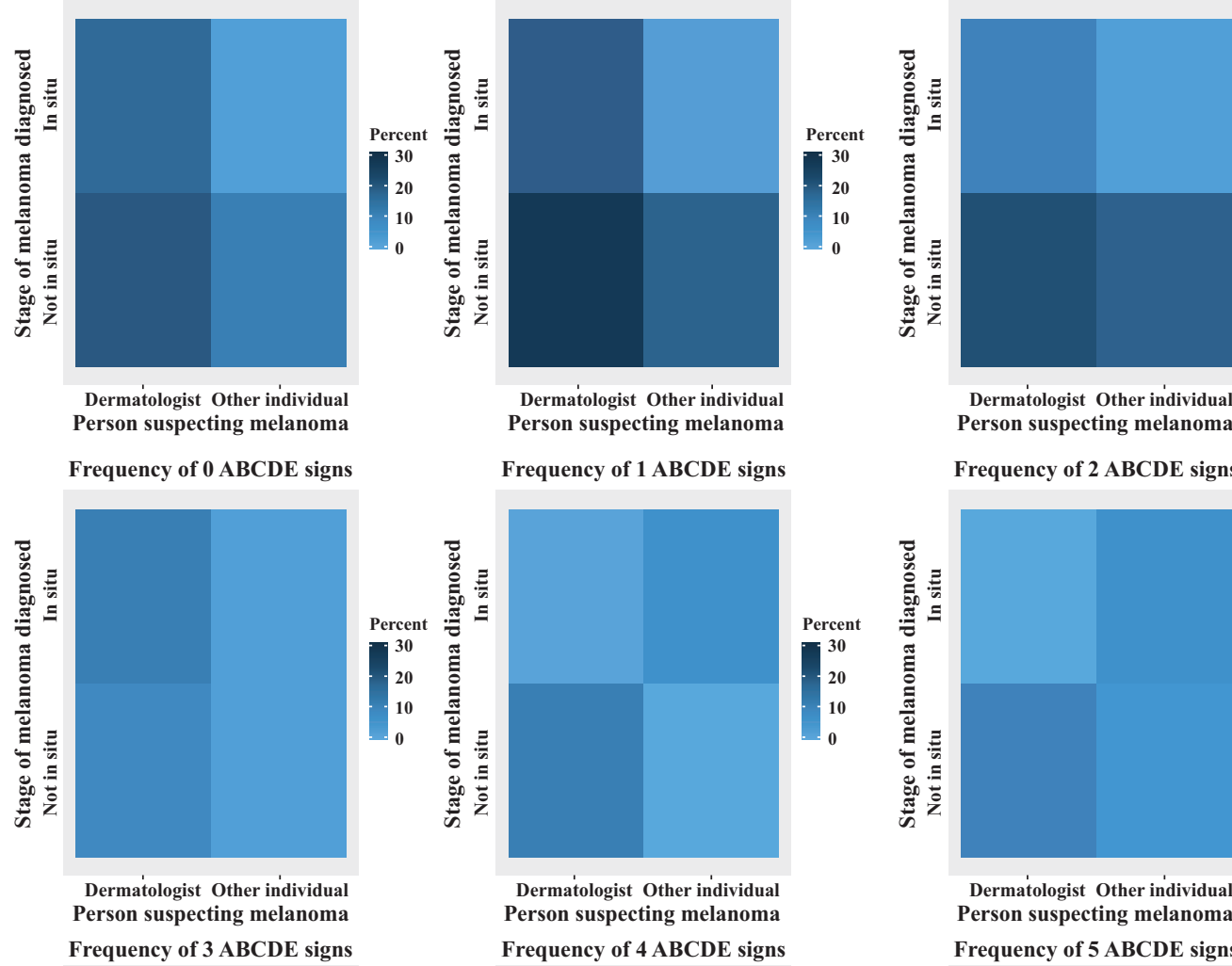
Person suspecting melanoma

Frequency of 2 ABCDE signs
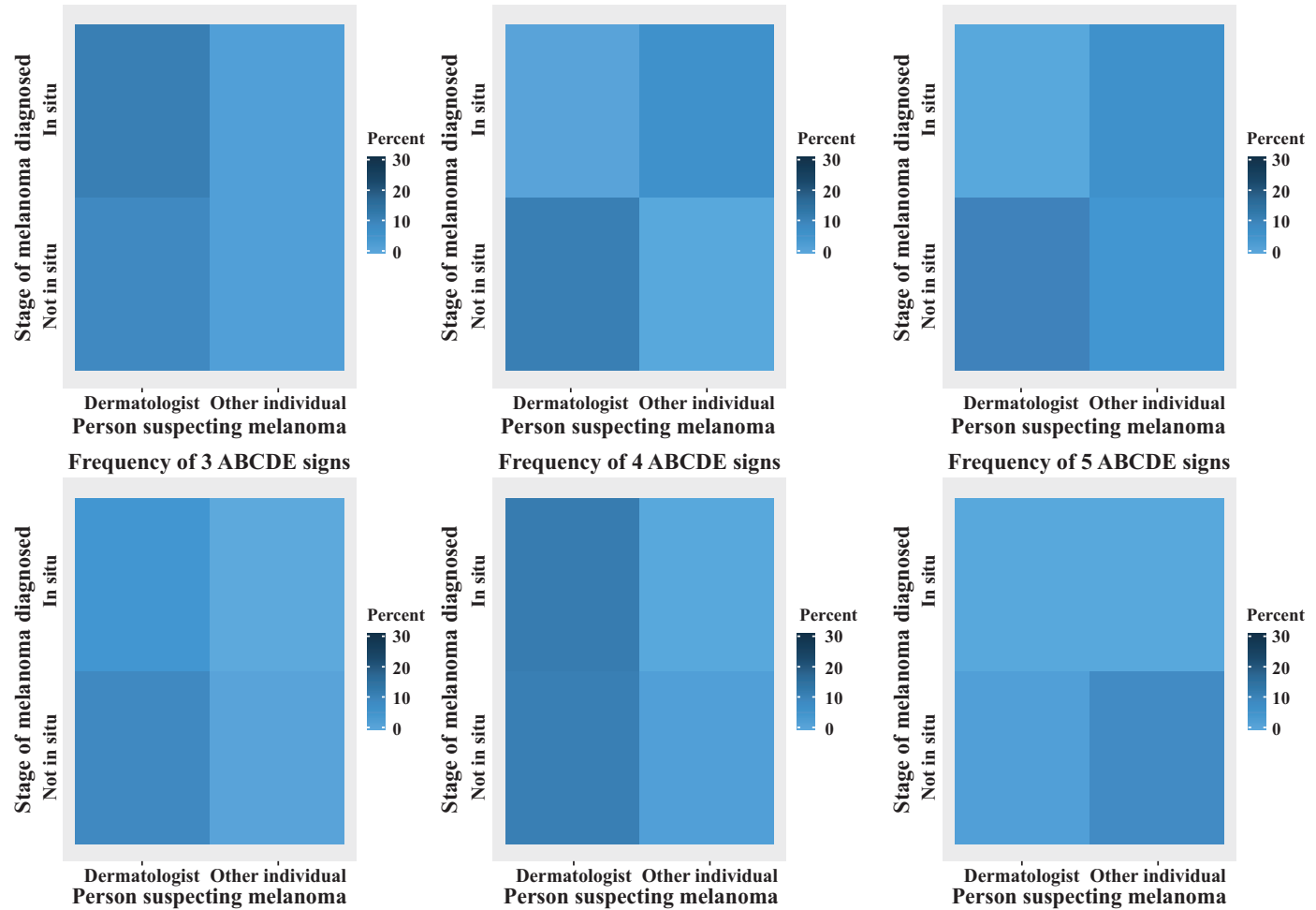

Figure 1. Average number of $\mathrm{ABCDE}$ signs and frequency of each sign and of each sign count according to stage of melanoma diagnosed and individual who first suspected the melanoma. 


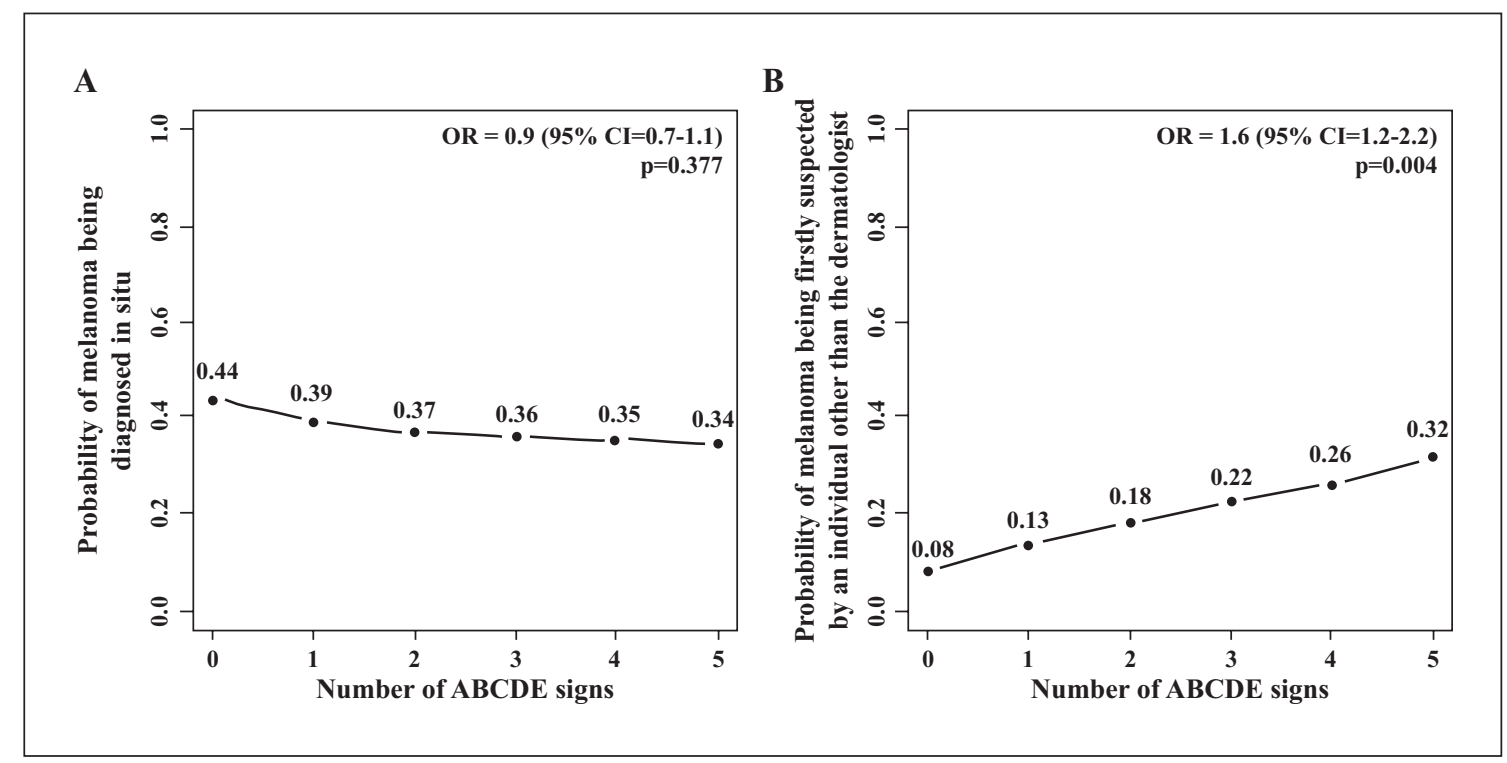

Figure 2. Dose-response function curves for the effect of the number of ABCDE signs on the probability of melanoma being diagnosed in situ (A) or being first suspected by an individual other than a dermatologist (B). A lesion with no ABCDE signs has a $44 \%$ probability of being diagnosed as in situ, and $8 \%$ of being first suspected by an individual other than a dermatologist. A lesion with five ABCDE signs has a $34 \%$ probability of being diagnosed as in situ, and $32 \%$ of being first suspected by an individual other than a dermatologist.

MM treatment is changing, especially for advanced stages, with the introduction of new anti-neoplastic biological response modifiers [29]. However, while effective, such therapeutic agents are expensive, prompting the need for effective strategies for prevention and early detection of MM. In fact, early detection and treatment of MM can reduce morbidity and mortality $[30,31]$ with investment in skin cancer primary prevention strategies, along with early detection, possibly resulting in lower costs for the society [32-39]. Throughout the world, dermatologists are unevenly geographically distributed, with most practising in urban areas, and this disparity has been increasing with time $[40,41]$. Correcting the workforce disparity is important for patient care. Meanwhile, patient education with teaching of the ABCDE rule is helpful to alert patients that something could be wrong with a skin lesion, particularly for patients with poor access to a dermatologist. However, this is insufficient, and we should focus on new strategies. In conclusion, we observed that frequent ABCDE signs were not associated with MM diagnosis in situ. However, we observed that a higher number of such signs were associated with a greater chance of MM being first suspected by an individual other than a dermatologist. Therefore, the ABCDE rule alone might not be sufficient for diagnosis of pre-invasive MM, but rather should be complemented by regular contact with a dermatologist, including thorough history and close inspection with full body examination assisted by dermoscopy. Nevertheless, our data support that this rule should still be taught to patients, particularly those with poor access to dermatologists, as this may prompt increased attention and identification of abnormal skin lesions.

Disclosure. Funding: none. Conflicts of interest: none.

\section{References}

1. Stang A, Ziegler S, Buchner U, Ziegler B, Jockel KH, Ziegler V. Malignant melanoma and nonmelanoma skin cancers in NorthrhineWestphalia, Germany: a patient- vs. diagnosis-based incidence approach. Int J Dermatol 2007; 46: 564-70.

2. Rubio-Casadevall J, Hernandez-Pujol AM, Ferreira-Santos MC, ef al. Trends in incidence and survival analysis in non-melanoma skin cancer from 1994 to 2012 in Girona, Spain: a population-based study. Cancer Epidemiol 2016; 45: 6-10.

3. de Giorgi V, Rossari S, Papi F, et al. Risk of second primary melanoma: how should be long follow-up be? Ratio of observed and expected cases. J Eur Acad Dermatol Venereol 2012; 26: 1454-5.

4. Miller AJ, Mihm MC Jr.. Melanoma. N Engl J Med 2006; 355: 51 65.

5. Forsea AM, Del Marmol V, de Vries E, Bailey EE, Geller AC. Melanoma incidence and mortality in Europe: new estimates, persistent disparities. BrJ Dermatol 2012; 167(5): 1124-30.

6. Arnold M, Holterhues $C$, Hollestein LM, et al. Trends in incidence and predictions of cutaneous melanoma across Europe up to 2015. J Eur Acad Dermatol Venereol 2014; 28: 1170-8.

7. Curchin DJ, Harris VR, McCormack CJ, Smith SD. Changing trends in the incidence of invasive melanoma in Victoria, 1985-2015. Med J Aust 2018; 208: 265-9.

8. Higgins HW 2nd., Lee KC, Galan A, Leffell DJ. Melanoma in situ: part I. Epidemiology, screening, and clinical features. J Am Acad Dermatol 2015; 73: 181-90, quiz 191-182.

9. Lallas A, Longo C, Manfredini M, et al. Accuracy of dermoscopic criteria for the diagnosis of melanoma in situ. JAMA Dermatol 2018; 154: 414-9.

10. Lallas A, Argenziano G, Zendri E, et al. Update on non-melanoma skin cancer and the value of dermoscopy in its diagnosis and treatment monitoring. Expert Rev Anticancer Ther 2013; 13:541-58. 
11. Thomas L, Puig S. Dermoscopy, digital dermoscopy and other diagnostic tools in the early detection of melanoma and follow-up of high-risk skin cancer patients. Acta Derm Venereol 2017; Suppl. 218: 14-21.

12. Grob JJ, Bonerandi JJ. The 'ugly duckling' sign: identification of the common characteristics of nevi in an individual as a basis for melanoma screening. Arch Dermatol 1998; 134: 103-4.

13. Mahon SM. Skin cancer prevention: education and public health issues. Semin Oncol Nurs 2003; 19: 52-61.

14. Drugge ED, Okundaye OI, Sarac RM, Drugge RJ. Melanoma screening using patient self-assessed risk and total body photography. Dermatol Online J 2019; 25: 13030/qt33h4r9bk.

15. llyas $M$, Costello $C M$, Zhang $N$, Sharma $A$. The role of the ugly duckling sign in patient education. I Am Acad Dermatol 2017; 77: 1088-95.

16. Friedman RJ, Rigel DS, Kopf AW. Early detection of malignant melanoma: the role of physician examination and self-examination of the skin. CA Cancer J Clin 1985; 35: 130-51.

17. Abbasi NR, Shaw HM, Rigel DS, et al. Early diagnosis of cutaneous melanoma: revisiting the $A B C D$ criteria. JAMA 2004; 292: 2771-6.

18. Corneli P, Zalaudek I, Magaton Rizzi G, di Meo N. Improving the early diagnosis of early nodular melanoma: can we do better? Expert Rev Anticancer Ther 2018; 18: 1007-12.

19. Heal CF, Raasch BA, Buettner PG, Weedon D. Accuracy of clinical diagnosis of skin lesions. Br J Dermatol 2008; 159: 661-8.

20. Chamberlain AJ, Fritschi L, Kelly JW. Nodular melanoma: patients' perceptions of presenting features and implications for earlier detection. J Am Acad Dermatol 2003; 48: 694-701.

21. Daniel Jensen J, Elewski BE. The ABCDEF Rule: combining the "ABCDE Rule" and the "Ugly Duckling Sign" in an effort to improve patient self-screening examinations. J Clin Aesthet Dermatol 2015; 8: 15.

22. Austin PC. Assessing the performance of the generalized propensity score for estimating the effect of quantitative or continuous exposures on binary outcomes. Stat Med 2018;37: 1874-94.

23. Guardabascio B, Ventura M. Estimating the dose-response function through the GLM approach. Munich Personal PePEc Archive.

2013. Available at https://mpra.ub.uni-muenchen.de/45013/.

24. Buuren SV, Groothuis-Oudshorn K. Mice: multivariate imputation by chained equations in R. J Stat Softw 2010;45: 1-68.

25. Thomas L, Tranchand P, Berard F, Secchi T, Colin C, Moulin G. Semiological value of $A B C D E$ criteria in the diagnosis of cutaneous pigmented tumors. Dermatology 1998; 197: 11-7.

26. Lomas A, Leonardi-Bee J, Bath-Hextall F. A systematic review of worldwide incidence of nonmelanoma skin cancer. Br J Dermatol 2012; 166: 1069-80.
27. Katalinic A, Kunze U, Schafer T. Epidemiology of cutaneous melanoma and non-melanoma skin cancer in Schleswig-Holstein, Germany: incidence, clinical subtypes, tumour stages and localization (epidemiology of skin cancer). Br J Dermatol 2003; 149: 1200-6.

28. Hoey SE, Devereux CE, Murray L, et al. Skin cancer trends in Northern Ireland and consequences for provision of dermatology services. Br J Dermatol 2007; 156: 1301-7.

29. Sekulic A, Migden MR, Lewis $K$, et al. Pivotal ERIVANCE basal cell carcinoma (BCC) study: 12-month update of efficacy and safety of vismodegib in advanced BCC. J Am Acad Dermatol 2015;72: 1021-6.e8.

30. Helfand M, Mahon SM, Eden KB, Frame PS, Orleans CT. Screening for skin cancer. Am J Prev Med 2001; 20: 47-58.

31. Wei EX, Qureshi AA, Han J, et al. Trends in the diagnosis and clinical features of melanoma in situ (MIS) in US men and women: a prospective, observational study. J Am Acad Dermatol 2016;75: 698-705.

32. Aitken JF, Youlden DR, Baade DP, et al. Generational shift in melanoma incidence and mortality in Queensland, Australia, 19952014. Int J Cancer 2017; 142: 1528-35.

33. Vallejo-Torres L, Morris S, Kinge JM, Poirier V, Verne J. Measuring current and future cost of skin cancer in England. J Public Health (Oxf) 2014; 36: 140-8.

34. Gordon LG, Rowell D. Health system costs of skin cancer and cost-effectiveness of skin cancer prevention and screening: a systematic review. Eur J Cancer Prev 2015; 24: 141-9.

35. Stratigos AJ, Forsea AM, van der Leest R, et al. Euromelanoma: a dermatology-led European campaign against nonmelanoma skin cancer and cutaneous melanoma. Past, present and future. $\mathrm{Br} J$ Dermatol 2012; 167: 99-104.

36. van der Leest RJ, de Vries E, Bulliard JL, et al. The Euromelanoma skin cancer prevention campaign in Europe: characteristics and results of 2009 and 2010. J Eur Acad Dermatol Venereol 201 1; 25: 1455-65.

37. Breitbart EW, Waldmann A, Nolte $S$, et al. Systematic skin cancer screening in Northern Germany. J Am Acad Dermatol 2012;66: 201-11.

38. Kyle JW, Hammitt JK, Lim HW, et al. Economic evaluation of the US Environmental Protection Agency's SunWise program: sun protection education for young children. Pediatrics 2008; 121 : e 1074-1084.

39. Forsea AM, del Marmol V. Impact, challenges and perspectives of Euromelanoma, a pan-European campaign of skin cancer prevention. J Eur Acad Dermatol Venereol 2013; 27: 1317-9.

40. Feng H, Berk-Krauss J, Feng PW, Stein JA. Comparison of dermatologist density between urban and rural counties in the United States. JAMA Dermatol 2018; 154: 1265-71.

41. Dai YX, Chen TJ, Chang YT. Urban-rural disparities in office-based dermatological services in Taiwan - a nationwide survey. Rural Remote Health 2018; 18: 4730. 